\title{
The natural history of impotence in diabetic men
}

\author{
D. K. McCulloch, R.J. Young, R. J. Prescott, I. W. Campbell and B. F. Clarke \\ Diabetic and Dietetic Department, Royal Infirmary, and Medical Computing and Statistics Unit, Edinburgh University, Edinburgh, \\ Scotland, UK
}

\begin{abstract}
Summary. The natural history of erectile impotence in diabetic men has been defined in a 5 -year prospective study of 466 patients initially aged $20-59$ years. Of the 275 who were originally potent, $78(28 \%)$ have become impotent. Five features present at first interview were found to be independently predictive of the subsequent development of impotence; age $(p<0.0001)$, alcohol intake $(p<0.0001)$, initial glycaemic control $(p=0.03)$, intermittent claudication $(p=0.04)$ and retinopathy $(p=0.05)$. The development of impotence was also significantly associated with the appearance of neuropathic symptoms $(p=0.003)$ and poor glycaemic control in the intervening 5 years $(p=0.01)$. Only 11 out of $128(9 \%)$ of those originally impotent regained potency; they were young, had short
\end{abstract}

duration of diabetes, and often features of psychogenic impotence. Those with impotence originally but no clinically apparent micro/macrovascular or neuropathic diabetic complications developed retinopathy $(p=0.001)$ and neuropathy $(p=0.01)$ more frequently than their comparable potent counterparts. It is concluded that diabetic impotence rarely reverses, that it is strongly associated with neuropathic and vascular complications of diabetes, and that moderation of alcohol consumption and improvement of glycaemic control are possible preventative factors.

Key words: Diabetes, impotence, alcohol, glycaemic control, retinopathy, neuropathy, claudication.
Although the prevalence of impotence in diabetes has frequently been described [1-7], the factors leading to its development and the prognosis of the established condition remain uncertain. We report a 5-year review of a cohort of diabetic men aged $20-59$ years whose sexual potency at the outset has been published previously [7]. The objectives were to identify clinical features associated with the development of impotence in those originally potent and to record the natural history of continuing sexual dysfunction and the development of other diabetic complications in those originally impotent.

\section{Subjects and methods}

Of the original 541 men interviewed [7], 63 had died, 36 had moved from the Edinburgh area and 22 were untraceable. Six patients refused to be re-interviewed and a further 11 were considered unsuitable (five for psychiatric reasons, three had cerebrovascular disease, one had sustained traumatic brain damage and two were no longer considered to have diabetes). Therefore 403 men were re-interviewed. The mean time interval between first and second interviews was 4 years 8 months (range 3 years 8 months to 6 years 2 months).

The questionnaire and methodology used were as described previously [7]. Thus in addition to assessing sexual function, direct enquiry was made as to drug therapy and macrovascular (ischaemic heart disease and peripheral vascular disease) or neurological disorders which might predispose to organic impotence. Impotence was defined as the absence of subjectively observed penile erections during the previous 6 months. Symptoms of peripheral and autonomic diabetic neuropathy were also sought but no objective tests of nerve function were performed. Retinopathy (direct fundoscopy through dilated pupils in darkened room) and proteinuria (Albustix) were documented. The average weekly alcohol intake of each was also estimated. For the purpose of analysis two groups were defined; those claiming to consume nil or less than 20 units of alcohol (one unit $=285 \mathrm{ml}$ beer or alcoholic equivalent in spirit/sherry/vermouth) per week were classified as 'moderate' drinkers and those consuming more than 20 units of alcohol per week 'heavy' drinkers. The number of cigarettes smoked daily was recorded.

Glycaemic control at the outset was assessed by taking the average of the six preceding clinic blood glucose values. Control was classified as 'good' if the mean blood glucose was $<9 \mathrm{mmol} / 1$, 'fair' if $9.1-13.9 \mathrm{mmol} / 1$ and 'bad' if $>14 \mathrm{mmol} / 1$. Diabetic control in the 5-year follow-up period was assessed as the mean of all the intervening clinic blood glucose results.

\section{Statistical analysis}

Statistical analysis was principally by the application of linear logistic models [8] which parallel the use of multiple regression for binomial response variables (e.g. potent/impotent). This allows simultaneous assessment of the influence of a number of variables on the occurrence of impotence while taking account of associations between the variables. Two tailed likelihood ration tests were employed to determine the significance of individual terms. 
Table 1. Clinical features predicting a development of impotence in 274 diabetic men originally potent during 5 years follow-up

\begin{tabular}{|c|c|c|c|c|c|c|}
\hline Clinical feature & & & $\begin{array}{l}\text { No. at } \\
\text { risk }\end{array}$ & \multicolumn{2}{|c|}{ No. developing } & $p$ \\
\hline Age (years) & $\begin{array}{l}20-34 \\
35-49 \\
50-59\end{array}$ & & $\begin{array}{r}88 \\
101 \\
86\end{array}$ & $\begin{array}{l}12 \\
37 \\
29\end{array}$ & $\begin{array}{l}14 \\
37 \\
34\end{array}$ & 0.0001 \\
\hline Alcohol intake & $\begin{array}{l}\text { 'Moderate' } \\
\text { 'Heavy' }\end{array}$ & $\begin{array}{l}(<20 \text { measures/week }) \\
(\geqslant 20 \text { measures/week })\end{array}$ & $\begin{array}{r}217 \\
58\end{array}$ & $\begin{array}{l}47 \\
31\end{array}$ & $\begin{array}{l}22 \\
53\end{array}$ & 0.0001 \\
\hline $\begin{array}{l}\text { Intermittent } \\
\text { claudication }\end{array}$ & $\begin{array}{l}\text { Absent } \\
\text { Present }\end{array}$ & & $\begin{array}{r}266 \\
9\end{array}$ & $\begin{array}{r}71 \\
7\end{array}$ & $\begin{array}{l}27 \\
78\end{array}$ & 0.04 \\
\hline Retinopathy & $\begin{array}{l}\text { None } \\
\text { Background } \\
\text { Advanced }\end{array}$ & & $\begin{array}{r}223 \\
39 \\
14\end{array}$ & $\begin{array}{r}60 \\
13 \\
5\end{array}$ & $\begin{array}{l}27 \\
33 \\
36\end{array}$ & 0.05 \\
\hline
\end{tabular}

${ }^{a}$ Based on fitting a linear logistic model (below) and tested using likelihood ratios

\section{Results}

\section{Factors associated with the development of impotence}

Two hundred and seventy-five men potent at the original interview were re-interviewed and $78(28 \%)$ had developed impotence, which in no case could be ascribed to recognised clinical factors, such as medication or obvious psychological cause. Those features present at the time of the original interview which correlated significantly with the subsequent development of impotence were age $(p<0.0001)$, alcohol intake $(p<0.0001)$, glycaemic control $(p=0.03)$, intermittent claudication $(p=0.04)$ and retinopathy $(p=0.05$; Table 1$)$. The fitted linear logistic model is: probability of impotence $=\mathrm{E}^{\mathrm{x}} /$ $\left(1-\mathrm{E}^{\mathrm{x}}\right)$ where $\mathrm{x}=-4.264+0.055$ age +1.504 alcohol +0.446 control +1.656 intermittent claudication +0.468 retinopathy (alcohol intake, glycaemic control, intermittent claudication and retinopathy take values 0 , 1 or 2, if appropriate, according to the category of the patient). Other clinical features originally ascertained which failed to show an association with the subsequent development of impotence, were duration of diabetes (even when insulin-treated patients were considered alone), type of treatment, proteinuria, and symptoms of peripheral and autonomic neuropathy. When all the predictive factors were retained in the analysis and additional associations were sought among the variables recorded at review, only the development of symptomatic peripheral neuropathy $(p=0.03)$ and poor glycaemic control in the intervening 5 years $(p=0.01)$ reached conventional levels of significance (though development of intermittent claudication was close, $p=0.07$ ).

The progress in sexual function of all the men re-interviewed with respect to the relevant factors other than age and glycaemic control (alcohol consumption, symptoms of peripheral/autonomic neuropathy and microor macrovascular complications) is shown in detail in
Table 2. It does not become clear from this, however, whether ethanol exerts its influence on the development of impotence in diabetic patients via an independent mechanism or mediated through an exacerbation of neuropathic and vascular complications of diabetes. Thus if the 'moderate' and 'heavy' drinkers who were initially potent and had no clinical evidence of diabetic complications are compared, although proportionately more of the latter developed impotence (18 out of 37 versus 27 out of 149), of those becoming impotent the 'heavy' drinkers also developed a higher proportion of other complications ( 10 out of 18 versus 10 out of 27 ). On the other hand, when testing for interaction between alcohol and other factors in the logistic model none were found to be statistically significant.

Forty-five men had impotence as an isolated symptom at the original interview, with no evidence of any macro/microvascular or neuropathic complications of diabetes, and seven regained potency. Among the remainder, only $17(45 \%)$ still had no other clinical pathology; ten developed vascular complications alone, four neuropathic symptoms alone and seven had evidence of both. Similarly those who had impotence and clinical evidence only of either vascular or neuropathic complications at the outset frequently developed the other (Table 2). Analysis confirmed that impotence per se is significantly associated with the subsequent development of retinopathy $(p=0.001)$ and symptoms of both peripheral $(p=0.01)$ and autonomic $(p=0.04)$ neuropathy.

\section{Analysis of deaths}

Among the 63 patients who died during the follow-up period, the mean age at death was $52.3 \pm 9$ years and the mean duration of diabetes was $16.7 \pm 9.6$ years. The causes of death were ascertained in all 63 cases. These were myocardial infarction (24), sudden unexplained 
Table 2. Progression during 5 years follow-up of sexual function, symptomatic neuropathy and vascular complications (microvascular + macrovascular) in 403 diabetic men initially aged $20-59$ years

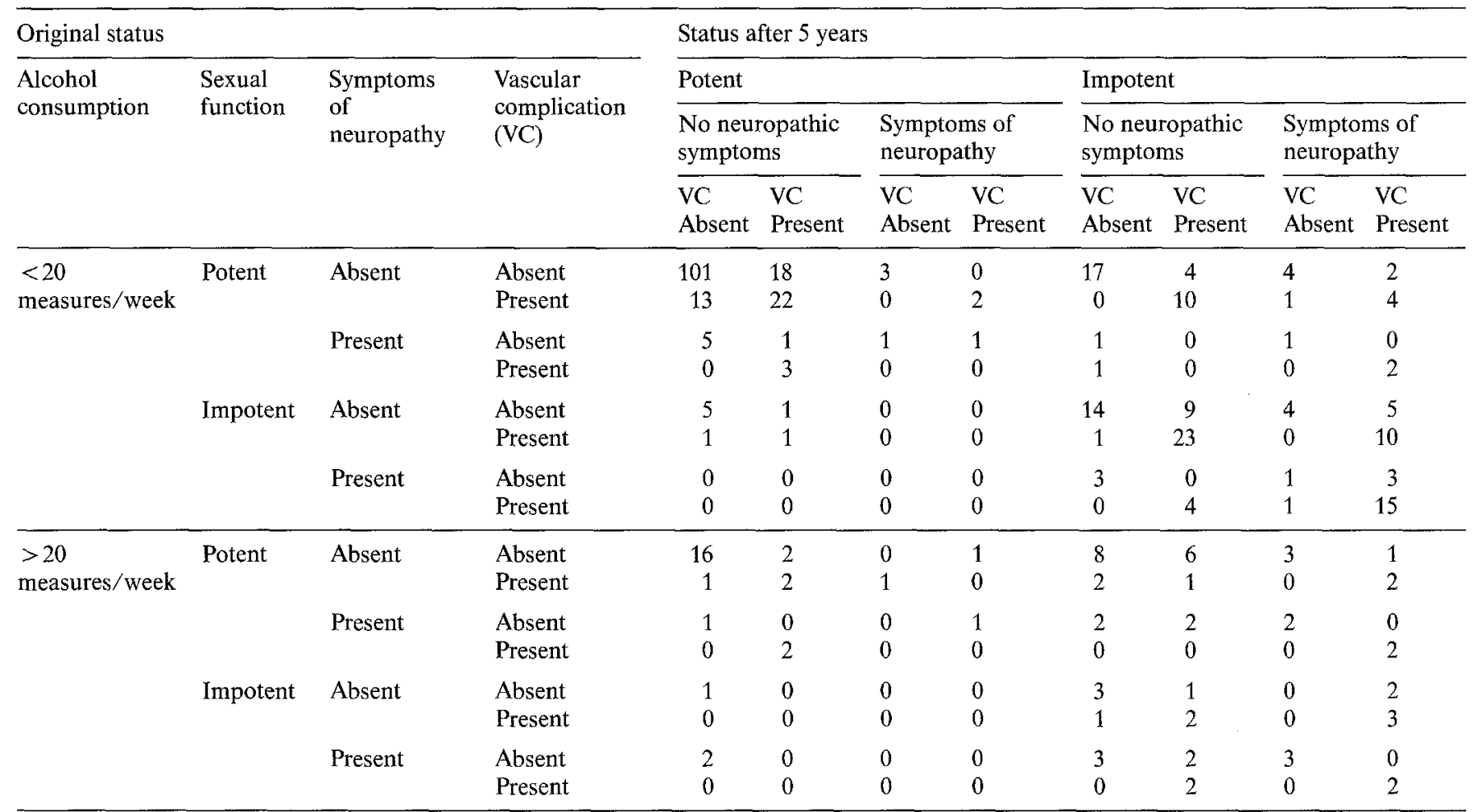

$\mathrm{VC}=$ vascular complications

deaths (8), chronic renal failure (6), cardiac failure (6), cerebrovascular accident (5), pneumonia (3), pulmonary embolism (2), and one case each of carcinoma of stomach, carcinoma of bronchus, hepatoma, cerebral tumour, carcinomatosis from an unidentified primary tumour, septicaemia following amputation for gangrene, cirrhosis of liver, ketoacidosis and hypoglycaemic coma.

Although $41(65 \%)$ of the deaths were in men who had been impotent at original interview, impotence per se was not significantly associated with mortality when tested with linear logistic models. Instead the features present at the outset, which were significantly predictive of death during the follow-up period, were age $(p<$ $0.0001)$, nephropathy $(p<0.0001)$, previous myocardial infarction $(p=0.0001)$, symptomatic autonomic neuropathy $(p=0.01)$ and retinopathy $(p=0.05)$. Thus, only six of the impotent men who died had isolated impotence. Of the remaining 35 , each had at least one major complication of diabetes when originally interviewed.

\section{Discussion}

This study has defined, for the first time, the natural history of impotence in diabetic men. Our original crosssectional study of impotence in 541 randomly selected diabetic men [7] identified a prevalence of $35 \%$. Of the 190 originally impotent patients, 41 had died during the
5 years, 21 were unavailable or unsuitable and 128 were re-interviewed. Only $11(9 \%)$ of those originally impotent had regained potency. Even among the 45 men with isolated impotence at the outset (i.e. no micro/macrovascular disease or symptomatic neuropathy) only seven $(16 \%)$ regained potency. Those recovering erectile function were significantly younger, had shorter duration of diabetes and often some psychological or organic factor had been present at initial interview which in retrospect was quite sufficient to account for temporary impotence. In the vast majority of cases, therefore, impotence developing in diabetic men is persistent. Impotence per se was also found to be significantly associated with the subsequent development of retinopathy and symptomatic peripheral and autonomic neuropathy but it did not confer an increased risk of mortality.

The original cross-sectional study demonstrated that established impotence was significantly related to age, retinopathy and symptomatic peripheral and autonomic neuropathy. The present follow-up study has identified some features which are predictive of the subsequent development of impotence. Age, alcohol intake, glycaemic control, peripheral vascular disease and retinopathy at the first interview were all associated with the development of impotence within 5 years. Age is, of course, a well-recognised associated feature of impotence, both in diabetes [1-7] and normal men [9]. However, it has not been demonstrated previously that high alcohol consumption and poor glycaemic control may 
be directly related to the development of impotence in diabetes. Furthermore these associations are independent of the known duration of diabetes.

The relationships between retinopathy, peripheral vascular disease and impotence support the proposition that vascular as well as neuropathic factors may play an important aetiological role in the pathogenesis of diabetic impotence [10-15]. By contrast, it may seem surprising that symptoms of peripheral and autonomic neuropathy were not predictive of the development of impotence since there is a well established association in cross-sectional studies $[1-7,14,15]$. The probable explanation is that the majority of those with symptoms of peripheral neuropathy $(63 \%)$ or autonomic neuropathy $(95 \%)$ at review were impotent at the outset. This conclusion is also supported by the observed tendency for neuropathy and impotence to develop concurrently during the follow-up period. Thus, impotence tends to come first. This study would therefore support a mixed vascular (micro + macro) and neuropathic aetiology for impotence in diabetic men.

Perhaps of greatest interest with respect to potential management is the relationship between glycaemia and alcohol. It is not unreasonable to imagine that the effect of poor glycaemic control on the development of impotence might be exerted through acceleration of diabetic complications. The association is relatively weak, however, although this may be due to the imprecise method of documenting glycaemia. Nevertheless, a strong link has been found with drinking, even though the documentation of alcohol consumption is notoriously inaccurate. This obviously poses the question as to whether alcohol per se can cause chronic impotence. Unfortunately we know of no relevant information from nondiabetic populations. In this study we have been able to show only that alcohol appears to have a uniform effect in increasing the prevalence of impotence irrespective of the preceding or parallel development of other diabetic complications.

From a practical viewpoint, our findings suggest that moderation of alcohol consumption and better glycaemic control might diminish the prevalence of impotence in diabetic men. However, once it has developed, impotence in diabetic men seems to be a persistent con- dition and other diabetic complications, if not already present, will often become manifest shortly after.

\section{References}

1. Rubin A, Babbott D (1958) Impotence and diabetes mellitus. JAMA 168: 198-500

2. Schöffling K (1960) Störungen der Kleindrüsenfunktion bei männlichen Zuckerkranken. Beitr Sexualforsch 19:1-83

3. Montenero P, Donatone E (1962) Diabète et activité sexuelle chez l'homme. Diabete Metab 10: 327-335

4. Ellenberg M (1971) Impotence in diabetes: the neurologic factor. Ann Intern Med 75: 213-219

5. Faerman I, Vilar O, Rivarola M, Rosner JM, Jadzinsky MN, Fox D, Perez Loret A, Bernstein-Hahn L, Saraceni D (1972) Impotence and diabetes. Studies of androgenic function in diabetic impotent males. Diabetes 21: 23-30

6. Kolodny RC, Kahn CB, Goldstein HH, Barnett DM (1974) Sexual dysfunction in diabetic men. Diabetes 23: 306-309

7. McCulloch DK, Campbell IW, Wu FC, Prescott RJ, Clarke BF (1980) The prevalence of diabetic impotence. Diabetologia 18: 279-283

8. Cox DR (1970) The linear logistic model. In: Analysis of binary data. Methuen, London, pp 14-29

9. Kinsey AC, Pomeroy WB, Martin CE (1948) Age and sexual outlet. In: Sexual behaviour in the human male. Saunders, Philadelphia, pp 218-262

10. Gaskell $P$ (1971) The importance of penile blood pressure in cases of impotence. Can Med Assoc J 105: 1047-1051

11. Abelson D (1975) Diagnostic value of the penile pulse and blood pressure. A Doppler study of impotence in diabetics. J Urol 113: $636-639$

12. Ruzbarsky V, Michal V (1977) Morphological changes in the arterial bed of the penis with ageing. Relationship to the pathogenesis of impotence. Invest Urol 15: 194-199

13. Michal V (1982) Arterial disease as a cause of impotence. Clin Endocrinol Metab 11: 725-748

14. Rundles RW (1945) Diabetic neuropathy; general review with report of 125 cases. Medicine (Baltimore) 24: 111-160

15. Martin MM (1953) Involvement of autonomic nerve fibres in diabetic neuropathy. Lancet 1: $560-565$

Received: 15 August 1983

and in revised form: 28 March 1984

Dr. RJ Young

Diabetic and Dietetic Department

Royal Infirmary

Edinburgh EH3 9YW

Scotland UK 